
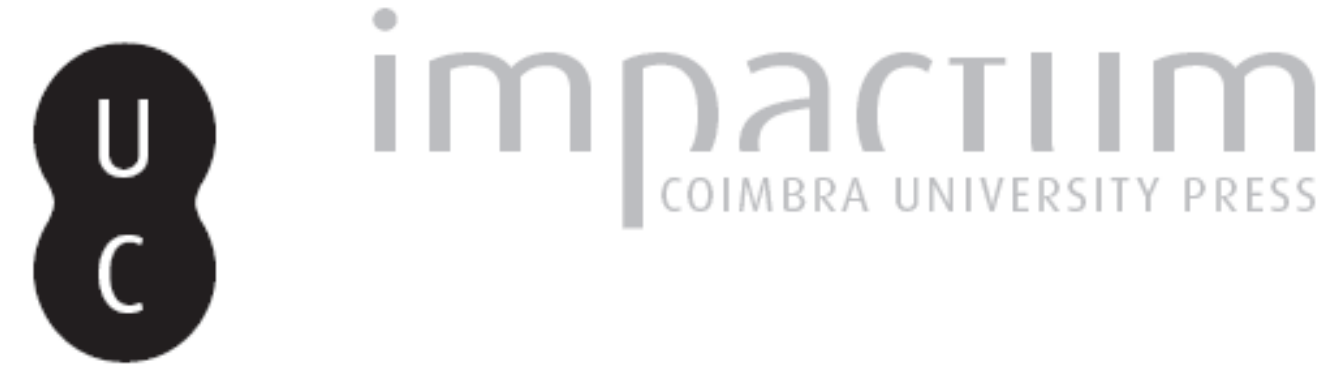

\title{
[Recensão a] D'Amicone, ELVIRA - Sarcófagos del Antiguo Egipto: jardineros de Amón en el Valle de las Reinas
}

\author{
Autor(es): $\quad$ Araújo, Luís Manuel \\ Publicado por: Centro de História da Universidade de Lisboa \\ URL \\ persistente: \\ URI:http://hdl.handle.net/10316.2/23657 \\ DOI: \\ DOI:http://dx.doi.org/10.14195/0871-9527_21_19 \\ Accessed : $\quad$ 26-Apr-2023 08:24:26
}

A navegação consulta e descarregamento dos títulos inseridos nas Bibliotecas Digitais UC Digitalis, UC Pombalina e UC Impactum, pressupõem a aceitação plena e sem reservas dos Termos e Condições de Uso destas Bibliotecas Digitais, disponíveis em https://digitalis.uc.pt/pt-pt/termos.

Conforme exposto nos referidos Termos e Condições de Uso, o descarregamento de títulos de acesso restrito requer uma licença válida de autorização devendo o utilizador aceder ao(s) documento(s) a partir de um endereço de IP da instituição detentora da supramencionada licença.

Ao utilizador é apenas permitido o descarregamento para uso pessoal, pelo que o emprego do(s) título(s) descarregado(s) para outro fim, designadamente comercial, carece de autorização do respetivo autor ou editor da obra.

Na medida em que todas as obras da UC Digitalis se encontram protegidas pelo Código do Direito de Autor e Direitos Conexos e demais legislação aplicável, toda a cópia, parcial ou total, deste documento, nos casos em que é legalmente admitida, deverá conter ou fazer-se acompanhar por este aviso.

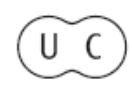



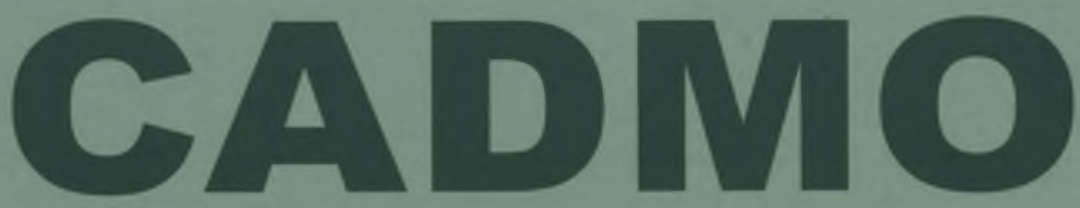

Revista de História Antiga

\author{
Centro de História \\ da Universidade de Lisboa
}

\title{
21
}

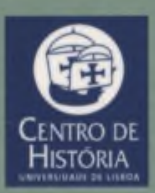

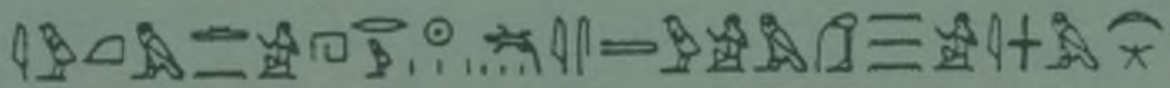

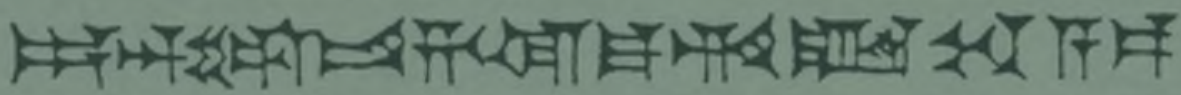

MHNIN AEI $\Delta \mathrm{E} \Theta \mathrm{EA}$ ПH$\Lambda \mathrm{HIA} \triangle \mathrm{E} \Omega$ 
formada pelo referido especialista e pelo Dr. Luís Raposo (director do Museu Nacional de Arqueologia), o Dr. Álvaro Figueiredo (bioarqueólogo do University College, Londres) e o autor da presente recensão. Para aconselhamento e acompanhamento prático do trabalho em curso, quer para as múmias quer para os respectivos sarcófagos e outros materiais funerários, foi criada uma eficaz equipa de consultoria científica formada pela Professora Salima Ikram (Universidade Americana do Cairo), Professor Rogério Sousa (Instituto Superior de Ciências da Saúde - Norte), Dra. Sandra Sousa (médica radiologista do IMI), Dr. Carlos Oliveira (médico radiologista do IMI e do Instituto Português de Oncologia) e Dr. Mathias Tissot (conservador do Museu Nacional de Arqueologia).

\section{Luís Manuel de Araújo}

ELVIRA D'AMICONE (dir.), Sarcófagos del Antiguo Egipto. Jardineros de Amón en el Valle de las Reinas, Barcelona: Museu Egipci de Barcelona, Fundació Arqueològica Clos, 2009, 176 pp., profusamente ilustrado, ISBN 978-84-932007-7-0

Este bem paginado e muito bem ilustrado volume é o que ficou de duradouro de uma experiência de colaboração entre o Museu Egípcio de Turim e o Museu Egípcio de Barcelona (Fundação Arqueológica Clos), que promoveram uma exposição na capital catalã num espaço criado especialmente para mostras temporárias - e a primeira a inaugurar o novo espaço foi precisamente a exposição que deu origem ao catálogo que aqui apreciamos.

A direcção editorial do projecto de publicação esteve a cargo de Elvira d'Amicone, conservadora do Museu Egípcio de Turim, e que também foi a comissária da exposição em Barcelona, enquanto Luis Manuel Gonzálvez, conservador do Museu Egípcio de Barcelona, se encarregou da coordenação geral.

A mostra apresentada no Museu Egípcio de Barcelona, que foi concebida e realizada pela Fundação Arqueológica Clos, esteve patente durante cerca de um ano, entre 13 de Março de 2008 a 13 de Abril de 2009, e exibiu peças cedidas pelo Museu Egípcio de Turim a que se juntaram algumas do museu anfitrião.

A exposição foi acompanhada pelo volume composto por duas partes fundamentais, a primeira que insere os artigos relacionados com o tema tratado, e que serve de preparação para a segunda parte, que é 
o catálogo das cerca de trinta peças egípcias expostas mais um conjunto de imagens e de manuscritos que contextualizam a sua descoberta.

A anteceder os artigos pode ler-se um sucinto texto de Jordi Clos Llombart, fundador e presidente da Fundação Arqueológica Clos (p. 7), seguido por outro texto assinado por Marina Sapelli Ragni e Giovanna Maria Bacci, ambas da Superintendência dos Bens Arqueológicos do Piemonte, organismo a que pertence o Museu Egípcio de Turim (p. 9), depois um outro de Alain Elkann, presidente da Fundação do Museu de Antiguidades Egípcias (p. 11) e ainda de Elvira d'Amicone e Mariàngela Taulé i Delor, directora-geral da Fundação Arqueológica Clos (p. 13). Segue-se um mapa do antigo Egipto (p. 14), um mapa detalhado do Vale das Rainhas, com destaque para os túmulos que foram descobertos por Ernesto Schiaparelli (p. 15) e uma cronologia (p. 17).

O primeiro artigo é da autoria de Elvira d'Amicone, que apresenta “El Antiguo Egipto y el Museo Egipcio de Turín» (pp. 20-29), registando as primeiras antiguidades egípcias que foram a base do acervo, o qual cresceu a partir dos objectos da colecção Drovetti e dos que foram encontrados em escavações dirigidas por Ernesto Schiaparelli, subsidiadas pelo próprio museu turinense.

A mesma autora encarregou-se de evocar "Ernesto Schiaparelli y las excavaciones en el Valle de las Reinas" (pp. 31-41), que decorreram entre 1903 e 1905, com bons resultados em termos de achados e de registo meticuloso dos objectos, merecendo ainda destacar a boa qualidade das fotos então ali obtidas, quer no exterior quer no interior dos túmulos.

E já que Schiaparelli escavou em Deir el-Medina entre 1905 e 1909, Luis Manuel Gonzálvez recorda «Deir el-Medina, la comunidad de los constructores de tumbas reales" (pp. 42-45), desde a instalação do povoado no reinado de Tutmés I, na XVIII dinastia, até finais da XX dinastia, quando cessaram os trabalhos dos operários que lá viviam.

$\mathrm{O}$ artigo seguinte é do mesmo autor, trazendo-nos "El "Diario de la Necrópolis" y los robos en los cementerios tebanos" (pp. 46-49), abordando um apreciável conjunto de textos redigidos pelos escribas de Deir el-Medina ao longo de duzentos anos que tratam das relações de trabalho e da vida quotidiana no local, incluindo greves e assaltos a túmulos reais.

Novamente Elvira d'Amicone, desta feita para introduzir algum do material exposto com «Los sarcófagos pintados de las excavaciones de Schiaparelli en el Valle de las Reinas y los "cultivadores de las flores de loto en el templo de Amón"» (pp. 50-59), datados da XXV dinastia, os quais foram achados em túmulos de membros da família real da $X X$ dinastia. 
Emma González Gil redigiu um esclarecedor artigo sobre «El ajuar funerario" (pp. 60-63), permitindo apreciar os vários objectos que, a par do sarcófago com a respectiva múmia, se colocavam no túmulo, como as estelas, mesas de oferenda, vasos de vísceras e estatuetas funerárias (até à Época Baixa conhecidas como chauabtis e depois como uchebtis, que por vezes são em grande número).

"La momificación» (pp. 64-67) é uma contribuição da anterior articulista, descrevendo todos os passos relacionados com a preparação do corpo nas suas várias fases que iam desde a inicial lavagem e evisceração, a mumificação, o embalsamamento, a recomposição do corpo e o enfaixamento e amuletização, para depois ser colocado no sarcófago.

"El mito de Isis y Osiris» (pp. 68-69) é lembrado por Pilar Casals Miret, com o aviso de que ele foi sobretudo de tradição oral mais do que registo escrito, além de que foi adaptado ao longo dos tempos em função das transformações sociais com variantes, até à bem conhecida tardia versão de Plutarco (séculos I-II d. C.).

A mesma autora vislumbrou «Los dos horizontes y los dioses del Occidente y del Oriente» (pp. 70-72), com a preponderância do culto solar (Ré-Horakhti) no seu percurso cíclico de oriente (iabet) manifestado em Khepri, o sol da alvorada, para ocidente (amentet), onde pontificava Atum associado a outras divindades.

A evocação de "Nut "la señora del cielo" (pp. 73-75) é também de Pilar Casals Miret, assinalando aqui a presença de uma divindade celestial feminina quando noutras culturas são divindades masculinas que tutelam o céu, além de que Nut tinha presença garantida nos temas decorativos do sarcófago e do túmulo por causa da ressurreição.

A série de artigos termina com a contribuição de Edoardo Guzzon, que analisou as «Familias del Valle de las Reinas» (pp. 76-81), ou melhor, as relações familiares que se podem detectar nos nomes e nos títulos dos proprietários dos sarcófagos que Ernesto Schiaparelli descobriu no Vale das Rainhas. As pp. 78-79 inserem um quadro genealógico que esclarece a relação entre os grupos familiares a partir da informação contida nos objectos, com os nomes em forma hieroglífica.

Depois vem o catálogo propriamente dito, e antes da apresentação dos sarcófagos e materiais associados mostra-se o modelo de uma máquina fotográfica usada em finais do século XIX (altura em que os objectos foram encontrados) e fotografias da época mostrando o interior de vários túmulos do Vale das Rainhas (príncipes Khaemuaset e Amenherkhopechef) e os trabalhos arqueológicos, bem como alguns desenhos de sarcófagos (pp. 85-97). 
O lote com os sarcófagos dos jardineiros do templo de Amon, os "cultivadores de flores de lótus", abre com Harua II (assim numerado para o distinguir de um seu tio Harua I), que permite, com os exemplares da época, aflorar a história da família em cinco gerações sob o poder da XXV dinastia de origem núbia (pp. 99-137). Estão representados Harua II, com um sarcófago parcialmente danificado (pp. 100-101), o seu tio Harua I, com a respectiva múmia e outros materiais (pp. 102105), a bisavó de Harua I, que se chamava Tadiisittahekataru e exibe os títulos de dona de casa (nebet-per) e nobre (chepés) em texto frontal (pp. 106-107).

Registe-se que a múmia de Harua I foi submetida a uma análise radiológica e a um restauro que permitiram, entre outros aspectos, elaborar uma hipótese de reconstrução facial, em tarefas inseridas num projecto de investigação antropológica organizado pelo Museu Egípcio de Turim. O essencial das acções empreendidas consta nas pp. 108-109, com a análise de tomografia axial computorizada (TAC) da múmia de Harua I e hipótese de reconstrução facial. É deveras interessante e ilustrativo verificar a composição da equipa reunida para o efeito, a qual integrou especialistas como Maria Cristina Martina e Giovani Gandini (Instituto de Radiologia de Diagnóstico e Intervenção da Universidade de Turim), Francesco Cesarini (Estrutura Complexa de Radiodiagnóstico ASL 18, Asti), Valter Capussotto e Guiliano Andrea (Gabinete Interregional de Polícia Científica do Piemonte e Vale de Aosta, Turim), Guaschino Michelle (Laboratório de Efeitos Especiais, Turim), Rosa Boano (Universidade de Turim, Departamento de Biologia Animal e do Homem, Laboratório de Antropologia), Renato Grilleto (Museu de Antropologia e Etnografia da Universidade de Turim) e Maurizio Cela (Polícia de Bolzano).

Quanto ao restauro, recuperação de fragmentos e consolidação de materiais, foram tarefas que estiveram a cargo de equipas de especialistas das firmas Paolo Malvisi Restauri (múmia de Harua I) e Nicola Restauri (sarcófago), enquanto os pequenos objectos evocativos do lótus e da sua plantação foram tratados por Luigi Vigna, sendo de sublinhar que a Fundação Arqueológica Clos financiou os trabalhos relacionados com a múmia. A descrição dos processos utilizados vem nas pp. 110-111.

Os outros materiais exibidos estão descritos nas pp. 112-121, com os sarcófagos de Mentuirdis, que se apresenta como cultivador de flores de lótus do templo de Amon, e de sua irmã Takhauienbastet (sem títulos), e o sarcófago de Nesikhonsuuennekhi, que foi, segundo a inscrição, chefe dos cultivadores de flores de lótus do templo de Amon, controlando por isso as actividades dos jardineiros amonianos (pp. 122-123). 
Seguem-se, para uma maior abrangência do tempo da XXV dinastia, vários modelos de sarcófagos da época de Harua II, Mentuirdis e Nesikhonsuuennekhi, como os que foram feitos para Sekheperamon, Ruru e Hor (pp. 126-129), para Nakhtkhonsu (pp. 130-131), um outro Hor, e ainda Nesiamenemipet (ou Nesiamenemope), Basaenmut (pp. 132-133), e o casal Irtieru e Nesiamondjamut, respectivamente avô e avó de Harua II (pp. 134-137). O núcleo expositivo dedicado aos sarcófagos fecha com textos explicativos de alguns especialistas que participaram no restauro dos materiais: Luigi Vigna faculta notas históricas e tecnológicas acerca das técnicas de realização e restauração dos sarcófagos (pp. 138-141), Paola lacomussi e Giuseppe Rossi divulgam o seu diagnóstico colorimétrico sobre a luz, os materiais, com o léxico descritivo (pp. 142-144) e Angelo Agostino oferece a sua análise de fluorescência com raios $\mathrm{X}$ e a análise cromática sobre amostras de cores dos sarcófagos (pp. 144-155).

O núcleo final, com textos de Elvira d'Amicone e de Luis Manuel Gonzálvez, serve para evocar o lótus no antigo Egipto, visto como uma flor divina, recorrendo a peças onde a célebre planta está representada, com hipopótamos de faiança azul, modelos de remos com desenhos de lótus, um prato de faiança, fragmento pintado, "colher" de perfume de madeira lotiforme, um friso, pequeno contentor e pequena tampa representando um lótus invertido (pp. 157-162). Depois de uma referência ilustrada sobre o azul egípcio e como se obtinha (p. 163) seguem-se mais materiais que evocam o lótus, como estelas e fragmentos murais, terminando com uma estátua de Amen-hotep, que era inspector dos jardins de Amon (pp. 164-171).

A bibliografia ocupa as $\mathrm{pp} .173-175$, rematando um volume que certamente agradará aos muitos leitores que se interessam por temas relacionados com o antigo Egipto, e que pode adrede proporcionar aos estudiosos que se debruçam sobre os aspectos ligados ao tratamento e exposição de materiais fúnebres, entre os quais avultam as múmias e os sarcófagos, boa matéria para reflexão e aprendizagem.

\section{Luís Manuel de Araújo}

JOSÉ NUNES CARREIRA, Mitos e Lendas Hititas, Lisboa: Edições Colibri, 2010, 148 pp., ISBN 978-972-772-938-8

No seio das antigas culturas pré-clássicas são bem conhecidos os mitos e lendas do antigo Egipto ou os da antiga Mesopotâmia, entre outros, 